\title{
Ischemic Strokes: Observations from a Hospital Based Stroke Registry in Bangladesh
}

\author{
Nirmalendu Bikash Bhowmik, ${ }^{1}$ Aamir Abbas, ${ }^{2}$ Mohammad Saifuddin, ${ }^{1}$ \\ Md. Rashedul Islam, ${ }^{1}$ Rumana Habib, ${ }^{1}$ Aminur Rahman, ${ }^{1}$ Md. Amirul Haque, ${ }^{1}$ \\ Zahid Hassan, ${ }^{3}$ and Mohammad Wasay ${ }^{2}$ \\ ${ }^{1}$ Department of Neurology, BIRDEM General Hospital, 122 Kazi Nazrul Islam Avenue, Shahbag, Dhaka 1000, Bangladesh \\ ${ }^{2}$ Department of Medicine, The Aga Khan University \& Hospital, Stadium Road, Karachi 74800, Pakistan \\ ${ }^{3}$ Department of Physiology and Molecular Biology, Bangladesh University of Health Sciences (BUHS), \\ 125/1 Mirpur-1, Dhaka, Bangladesh
}

Correspondence should be addressed to Nirmalendu Bikash Bhowmik; bhowmiknbb24@gmail.com

Received 1 March 2016; Revised 19 May 2016; Accepted 14 June 2016

Academic Editor: Wai-Kwong Tang

Copyright (C) 2016 Nirmalendu Bikash Bhowmik et al. This is an open access article distributed under the Creative Commons Attribution License, which permits unrestricted use, distribution, and reproduction in any medium, provided the original work is properly cited.

\begin{abstract}
Background. Stroke is an important morbidity for low and middle income countries like Bangladesh. We established the first stroke registry in Bangladesh. Methods. Data was collected from stroke patients who were admitted in Department of Neurology of BIRDEM with first ever stroke, aged between 30 and 90 years. Patients with intracerebral hemorrhage, subarachnoid and subdural hemorrhage, and posttrauma features were excluded. Results. Data was gathered from 679 stroke patients. Mean age was 60.6 years. Almost $68 \%$ of patients were male. Small vessel strokes were the most common accounting for $45.4 \%$ of all the patients followed by large vessel getting affected in 32.5\% of the cases. Only $16(2.4 \%)$ died during treatment, and $436(64.2 \%)$ patients had their mRS score of 3 to 5. Age greater than 70 years was associated with poor outcome on discharge [OR 1.79 (95\% CI: 1.05 to 3.06)] adjusting for gender, duration of hospital stay, HDL, and pneumonia. Age, mRS, systolic blood pressure, urinary tract infection, pneumonia, and stroke severity explained the Barthel score. Conclusion. Mortality was low but most of patient had moderate to severe disability at discharge. Age, mRS, systolic blood pressure, urinary tract infection, pneumonia, and stroke severity influenced the Barthel score.
\end{abstract}

\section{Introduction}

Stroke, an important morbidity in the context of sustainability development goals (SDGs), is the leading cause of disability in the Asian population $[1,2]$. Low and middle income countries have a higher burden and mortality because of stroke and it is increasing over time [3-6]. Stroke becomes important health problem for Bangladesh as more than 25\% of its population live below the poverty line [7]. Bangladesh is third largest country among south Asian countries after India and Pakistan with a population of 160 billion. South Asian countries constitute $22 \%$ of world population and $40 \%$ of developing world and account for more than $40 \%$ of global stroke death [8].
A large number of preventable deaths in Bangladesh occur due to stroke $[9,10]$. Stroke ranks third among causes of death in Bangladesh [9]. Mortality due to stroke increased from $6 \%$ to around $9 \%$ from 2006 to 2011 [9]. Individuals in Bangladesh having age of 40 years or more have a stroke prevalence of $0.3 \%$ and its prevalence increases to $1 \%$ in individuals aged 70 years or more [10]. Gender and age are two important factors affecting stroke prevalence in Bangladesh [10]. Risk factors for stroke in Bangladesh include hyperlipidemia, diabetes mellitus, heart disease, cigarette smoking, oral contraception use, and previous history of TIA $[11,12]$. Frequencies of these risk factors are comparable to other south Asian countries [8]. The majority of the stroke patients suffer from ischemic stroke which had a better 
prognosis as compared to the hemorrhagic stroke $[13,14]$. Bangladesh due to its large population lacks the requisite health infrastructure and trained human resource needed to deal with the high burden of stroke [15].

World Health Organization (WHO) recommends 3-step approach to establish stroke surveillance system. First step should capture data about stroke in the hospital giving information about treatment and mortality of the stroke patients. In the subsequent steps WHO recommend capturing stroke related fatal and nonfatal events in the community [16]. Experiences from the region have recommended establishing a hospital based surveillance system [17]. Establishing such a system for low and middle income countries in the community might be challenging because of the cost implications [17, 18]. In order to improve the quality of evidence generated it is recommended that surveillance system using standardized approaches be establish [16].

Studies done on stroke in Bangladesh have quantified the prevalence of stroke but studies collected information on limited number of the relevant variables [19]. In light of this limitation of previous data we established stroke registry in Bangladesh to get information on relevant and important risk factors of stroke. The aim of this registry was to regularly quantify burden of various types of stroke in Bangladesh and to identify their risk factors. We intended to compare the results from this registry to the risk factors for stroke identified in other countries of the region like India and Pakistan. This piece of information is critical for evidence based resource allocation at health care centers.

\section{Materials and Methods}

A total number of 679 subjects with first ever stroke consecutively admitted in the Department of Neurology of Bangladesh Institute of Research and Rehabilitation in Diabetes, Endocrine and Metabolic Disorders (BIRDEM) General Hospital, were recruited for the study during January 2011 to February 2013.

Inclusion criteria were age between 30 and 90 years and patients presenting with first ever stroke. Diagnosis of stroke was done on the basis of findings from Neuroimaging (either of CT or MRI). Patients with intracerebral hemorrhage, subarachnoid and subdural hemorrhage, and posttrauma features and history of previous stroke were excluded from the study. A structured questionnaire as appended was used to collect information on demographic variables, stroke severity (with the help of modified Rankin Scale [mRS] and National Institute of Health Stroke Scale [NIHSS]), stroke subtype using TOAST criteria, vascular risk factors, and stroke workup. Patients were labeled as hypertensive if systolic blood pressure was greater than $140 \mathrm{mmHg}$ or/and diastolic blood pressure was greater than $90 \mathrm{mmHg}$ during repeated measurements during the patient management in the hospital or if the patient was on antihypertensive drugs at the time of admission. We classified patient as diabetic if selfreported fasting glucose level of the patient was $120 \mathrm{mg} / \mathrm{dL}$ or more or if the patient was on hypoglycemic agents or insulin. Patients having serum high density lipid of $100 \mathrm{mg} / \mathrm{dL}$ or less and/or serum low density lipid of $100 \mathrm{mg} / \mathrm{dL}$ or more and/or fasting serum cholesterol of $200 \mathrm{mg} / \mathrm{dL}$ or more were labeled as having dyslipidemia. Smokers were the patients who had smoked ten or more cigarettes for ten or more years. Electrocardiogram was used to check for atrial fibrillation. Carotid Doppler was used to identify patients having carotid stenosis. Left ventricular dysfunction was assessed using echocardiogram. Patients having $30 \%$ or less ejection fraction were classified as having severe left ventricular dysfunction.

Patients or their next of kin were briefed about the purpose and nature of the study. Written consent was obtained from the patients or their next of kin in case of incapacitation of the patients. Ethical approval was obtained from Ethical Review Committee of Bangladesh Diabetic Association, the parent body that runs BIRDEM General Hospital.

Upon receipt of the consent of the patients or their nearest relative's consent qualified medical personnel, not below senior medical officer and assistant register, examined and interviewed the patient or the patient's attendant about past medical and personal history and recorded the variable of interest. Investigations, ECG, CT scan, MRI, echocardiography, and carotid Doppler, only pertinent to clinical presentations, were advised. Standardized Data Collection Form was used in recruiting patients.

On discharge patients or their attendants were asked to report the BIRDEM neurology clinic after four weeks and then after six months. Assigned medical personnel were in contact to follow the progress over telephone in the four weeks.

Data were managed using Statistical Package for Social Science (SPSS) for Windows Version 19. In the presentation data were expressed as mean $\pm \mathrm{SD}$, median (minimummaximum), and number (percent) as appropriate. Unpaired Student's $t$-test, proportion test, and Chi-squared tests were performed, where applicable, to calculate statistical difference between corresponding groups and/or association between groups. $P$ value $<0.05$ was taken as level of significance. Logistic regression was used to compute adjusted odds ratio for poor outcomes of stroke. Linear regression was done to identify variables explaining Barthel score.

\section{Sample Size}

Sample size was calculated using OpenEpi, Version using formula [DEFF $* N p(1-p)] /\left[d^{2} / Z_{1-\alpha / 2}^{2} *(N-1)+p *(1-p)\right]$. Using this formula we planned to recruit a minimum of 600 stroke patients to capture the anticipated prevalence of stroke risk factors to be $50 \%$ among the stroke patients, margin of error to be $4 \%$, and level of significance to be $5 \%$.

\section{Results}

This stroke registry gathered data from 679 stroke patients in BIRDEM General Hospital, Dhaka, Bangladesh. Mean age of the stroke patients was 60.6 years; the majority of patients $(67.7 \%)$ were male. Only $16.5 \%$ of the patients had age greater than 70 years. Most patients (66\%) had an age between 45 and 70 years. Only 72 (11\%) patients (50 men and 22 women) were 
TABLE 1: Known risk factors $(n=679)$.

\begin{tabular}{|c|c|}
\hline Risk factors & $n(\%)$ \\
\hline Diabetes & $506(74.5)$ \\
\hline Hypertension & $504(74.2)$ \\
\hline Dyslipidemia & $48(7.1)$ \\
\hline IHD & $81(11.9)$ \\
\hline Current smoker $n=629$ & $110(17.5)$ \\
\hline Past smoker $n=629$ & $82(13.0)$ \\
\hline Chewing tobacco & $191(28.1)$ \\
\hline Family history of stroke $n=644$ & $193(30.0)$ \\
\hline Family history of IHD $n=644$ & $134(20.8)$ \\
\hline Atrial fibrillation & $8(1.2)$ \\
\hline $\mathrm{HDL} \leq 40(614)$ & $433(70.5)$ \\
\hline LDL > $100(608)$ & $420(69.1)$ \\
\hline Total cholesterol > $200(615)$ & $264(42.9)$ \\
\hline $\begin{array}{l}\text { Dyslipidemia }(\mathrm{chol}>200 \text { or LDL }>100 \\
\text { or HDL }<40)(614)\end{array}$ & $571(93)$ \\
\hline \multicolumn{2}{|l|}{ In-hospital complications } \\
\hline DVT & $2(0.3)$ \\
\hline Pneumonia & $60(8.8)$ \\
\hline UTI & $54(8.0)$ \\
\hline Pulmonary edema & $1(0.1)$ \\
\hline Phlebitis/cellulitis & $6(0.9)$ \\
\hline Sepsis & $6(0.9)$ \\
\hline Hematuria & $2(0.3)$ \\
\hline Seizers & $26(3.8)$ \\
\hline
\end{tabular}

Deep venous thrombosis: DVT, ischemic heart disease: IHD, high density lipoprotein: HDL, low density lipoprotein: LDL, and urinary tract infection: UTI.

less than 45 years. Diabetes, hypertension, family history of stroke, and ischemic heart disease were common risk factors identified at the time of admission (Table 1).

Small vessel strokes were the most common accounting for $45.4 \%$ of all the patients followed by large vessel stroke in $32.5 \%$ of the cases. Cardioembolic stroke was present in $4.9 \%$ while etiology was not defined in $17.2 \%$ of the stroke cases. Out of a total 673 patient among whom NIHSS score was recorded 121 patients $(17.8 \%)$ had severe stroke (NIHSS score greater than 14). Dyslipidemia was present in $93 \%$ of the cases (Table 1). Most common infarct location was in parietal lobe found in 236 (34.8\%), followed by basal ganglia in 184 (27.1\%) and internal capsule 178 (26.2\%), of the patients (Table 2).

ECG was done for all the patients and there was cardiac morbidity on ECG in $50.2 \%$ of these patients. Ischemia was the most common cardiac abnormality detected on ECG and was present in $28.1 \%$ of the patients. Other cardiac abnormalities detected on ECG included left ventricular hypertrophy (6.3\%), old infarct (5.4\%), left bundle branch block (4.1\%), left atrial dilation (3.7\%), atrial fibrillation (1.2\%), and right bundle branch block (0.9\%). Pneumonia was the most common complication found in $60(8.8 \%)$ subjects while UTI was found in 54 (8.0\%) subjects (Table 1).
TABLE 2: Infarct location $(n=679)$.

\begin{tabular}{lc}
\hline Location of infarct & $n(\%)$ \\
\hline Front & $38(5.6)$ \\
Parietal & $236(34.8)$ \\
Temporal & $39(5.7)$ \\
Occipital & $34(5.0)$ \\
Basal ganglia & $184(27.1)$ \\
Thalamus & $45(6.6)$ \\
Subcortical & $6(0.9)$ \\
Internal capsule & $178(26.2)$ \\
Midbrain & $16(2.4)$ \\
Pons & $41(6.0)$ \\
Medulla & $12(1.8)$ \\
Cerebellar & $47(6.9)$ \\
\hline
\end{tabular}

Mean stay in hospital was 7.8 days (standard deviation, 3.9). All the patients were assessed for their outcomes using mRS (modified Rankin Scale) score at discharge from hospital. Only 16 (2.4\%) of the died during treatment, 436 (64.2\%) patients had their mRS score from 3 to 5 (moderate to severe disability) while 227 (33.4\%) of the patients had an mRS score equal to or less than 2 (no to mild disability).

By comparing gender it was shown that higher proportion of females had hypertension. Smoking and UTI were more common among males. Women had a slightly greater mean hospital stay. More males had favorable outcome on discharge as compared to females (Table 3 ).

Individuals with age less than or equal to 45 years had a higher proportion of diastolic blood pressure and carotid stenosis while UTI and pneumonia were more commonly found in patients with age greater than 45 years (Table 4).

Elderly patients (age $>70$ years) were more likely to have pneumonia, severe left ventricular dysfunction, and hypertension. More patients in the age group less than or equal to 70 had diastolic blood pressure, diabetes mellitus, and smoking. More patients in this group had favorable outcomes at discharge (mRS on discharge 0 to 2) (Table 5).

Odds of poor outcome on discharge were for those who had an age greater than 70 years being 1.79 (95\% CI: 1.05 to 3.06) as compared to those having an age less than or equal to 70 years when adjusted for gender, number of days of hospital stay, HDL, and pneumonia. On the basis of linear regression factors explaining Barthel score there were $\mathrm{mRS}$, age, systolic blood pressure, urinary tract infection, pneumonia, and stroke severity (Table 6).

\section{Discussion}

To the best of our knowledge this is the first registry which intended to collect data on a wide range of stroke patients from a tertiary care center in Bangladesh. There are certain limitations as this registry was maintained only in one center. There were missing data on some of the variables. Same set of investigations could not be performed on all the patients. We were unable to follow up the patients after discharge and therefore we could not find out the mortality 
TABLE 3: Risk factors of stroke patient by gender.

\begin{tabular}{|c|c|c|c|}
\hline Variable & Male $n=460$ & Female $n=219$ & $P$ value \\
\hline Age mean (SD) & $60.32(11.0)$ & $61.24(11.0)$ & 0.31 \\
\hline Systolic BP mean (SD) & $144.22(22.7)$ & $144.59(21.7)$ & 0.84 \\
\hline Diastolic BP mean (SD) & $84.79(12.1)$ & $84.31(12.3)$ & 0.63 \\
\hline RBS mean (SD) & $231.48(95.1)$ & $231.23(94.5)$ & 0.98 \\
\hline \multicolumn{4}{|l|}{ TOAST $n(\%)$} \\
\hline Large vessel & $148(32.2)$ & $73(33.3)$ & \multirow{4}{*}{0.81} \\
\hline Small vessel & $214(46.5)$ & $94(42.9)$ & \\
\hline Cardioembolic & $21(4.6)$ & $12(5.5)$ & \\
\hline Unknown etiology & $77(16.7)$ & $40(18.3)$ & \\
\hline \multicolumn{4}{|l|}{ Risk factors } \\
\hline $\mathrm{DM}(\mathrm{RBS}>200)$ & $237(57.8)$ & $118(60.5)$ & 0.53 \\
\hline HTN & $323(70.2)$ & $181(82.6)$ & 0.01 \\
\hline Dyslipidemia & $392(94.2)$ & $179(90.4)$ & 0.08 \\
\hline Smoking & $106(24.4)$ & $4(2.1)$ & $<0.01$ \\
\hline Carotid stenosis $>70 \%$ & $17(15.7)$ & $11(17.7)$ & 0.74 \\
\hline A-fib on ECG & $5(1.1)$ & $3(1.4)$ & 0.72 \\
\hline Severe LV dysfunction & $62(17.9)$ & $25(15.1)$ & 0.42 \\
\hline \multicolumn{4}{|l|}{ Investigations } \\
\hline MRI & $100(21.7)$ & $40(18.3)$ & 0.30 \\
\hline Echocardiography & $299(78.5)$ & $145(80.1)$ & 0.66 \\
\hline Carotid Doppler & $374(81.3)$ & $174(79.5)$ & 0.57 \\
\hline \multicolumn{4}{|l|}{ Complications } \\
\hline Pneumonia & $36(7.8)$ & $24(11.0)$ & 0.18 \\
\hline UTI & $26(39.3)$ & $32(18.7)$ & $<0.01$ \\
\hline Stroke severity NIHSS $>14$ & $79(17.2)$ & $42(19.2)$ & 0.52 \\
\hline \multicolumn{4}{|l|}{$\mathrm{mRs}$ at discharge } \\
\hline $0-2$ & $170(37.0)$ & $57(26.0)$ & \\
\hline $3-5$ & $279(60.7)$ & $157(71.7)$ & 0.02 \\
\hline 6 & $11(2.4)$ & $5(2.3)$ & \\
\hline Hospital mean stay & $7.5(3.7)$ & $8.5(4.2)$ & $<0.01$ \\
\hline
\end{tabular}

Atrial fibrillation: A-fib, blood pressure: BP, diabetes mellitus: DM, electrocardiogram: ECG, hypertension: HTN, left ventricular: LV, magnetic resonance imaging: MRI, National Institute of Health Stroke Scale: NIHSS, random blood sugar: RBS, standard deviation: SD, and urinary tract infection: UTI.

rate of these patients for standard time period. Despite these limitations this data provides useful information related to stroke types/subtypes, risk factors, gender, and age of stroke onset based differences among stroke patients enrolled at this large center in Dhaka, Bangladesh. This is probably the largest data set of stroke patients published from Bangladesh.

Mean age of the stroke patients which is around sixty years is consistent with findings from a similar stroke registry in Pakistan [20]. Most of the patients from a stroke registry in USA presented with stroke at an age of 71 years [21]. In Korea the mean age of patients getting registered is around 62 years [22]. In our sample the mean age of stroke patient was not affected by gender while stroke registry from France showed that mean age for female stroke patients was 70 years while it was 66 years for male patients [23].

The lower percentage of female stroke patients being registered implies either a low prevalence of stroke among
TABLE 4: Distribution of covariates among stroke patients with young age.

\begin{tabular}{|c|c|c|c|}
\hline Variable & $\begin{array}{c}\leq 45 \text { yrs } \\
n=72\end{array}$ & $\begin{array}{l}>45 \text { yrs, } \\
n=607\end{array}$ & $P$ value \\
\hline Systolic BP mean (SD) & $143.3(21.8)$ & $144.5(22.4)$ & 0.67 \\
\hline Diastolic BP mean (SD) & $88.7(13.5)$ & $84.2(11.9)$ & $<0.01$ \\
\hline RBS mean (SD) & $246.6(104.0)$ & $229.7(93.7)$ & 0.19 \\
\hline \multicolumn{4}{|l|}{$\operatorname{TOAST} n(\%)$} \\
\hline Large vessel & $25(34.7)$ & $196(32.3)$ & \multirow{4}{*}{0.89} \\
\hline Small vessel & $30(41.7)$ & $278(45.8)$ & \\
\hline Cardioembolic & $3(4.2)$ & $30(4.9)$ & \\
\hline Unknown etiology & $14(19.4)$ & $103(17.0)$ & \\
\hline Stroke severity NIHSS & $9.1(5.4)$ & $9.5(5.5)$ & 0.57 \\
\hline \multicolumn{4}{|l|}{ Risk factors } \\
\hline $\mathrm{DM}(\mathrm{RBS}>200)$ & $54(75.0)$ & $452(74.5)$ & 0.92 \\
\hline HTN & $51(70.8)$ & $453(74.6)$ & 0.49 \\
\hline Dyslipidemia & $60(92.3)$ & $511(93.1)$ & 0.82 \\
\hline Smoking & $14(19.4)$ & $96(15.8)$ & 0.43 \\
\hline Carotid stenosis $>70 \%$ & $5(38.5)$ & $23(14.6)$ & 0.03 \\
\hline A-fib on ECG & $1(1.4)$ & $7(1.2)$ & 0.86 \\
\hline Severe LV dysfunction & $12(22.6)$ & $75(16.3)$ & 0.25 \\
\hline \multicolumn{4}{|l|}{ Investigations } \\
\hline MRI & $18(25.0)$ & $122(20.1)$ & 0.33 \\
\hline Echocardiography & $49(77.8)$ & $395(79.2)$ & 0.80 \\
\hline Carotid Doppler & $51(70.8)$ & $446(73.5)$ & 0.63 \\
\hline \multicolumn{4}{|l|}{ Complications } \\
\hline Pneumonia & $2(2.8)$ & $58(9.6)$ & 0.06 \\
\hline UTI & $1(1.4)$ & $57(9.4)$ & 0.02 \\
\hline \multicolumn{4}{|l|}{$\mathrm{mRs}$ at discharge } \\
\hline $0-2$ & $28(38.9)$ & $199(32.8)$ & \multirow{3}{*}{0.55} \\
\hline $3-5$ & $42(58.3)$ & $394(64.9)$ & \\
\hline 6 & $2(2.8)$ & $14(2.3)$ & \\
\hline Hospital mean stay & $7.2(3.4)$ & $7.9(3.9)$ & 0.19 \\
\hline
\end{tabular}

Atrial fibrillation: A-fib, blood pressure: BP, diabetes mellitus: DM, electrocardiogram: ECG, hypertension: HTN, left ventricular: LV, magnetic resonance imaging: MRI, National Institute of Health Stroke Scale: NIHSS, random blood sugar: RBS, standard deviation: $\mathrm{SD}$, and urinary tract infection: UTI.

females or a lower access of female stroke patients to the tertiary care hospital. Paradoxically length of hospital stay and stroke severity on discharge were higher among females. We found that though a very small number of women smoked which implies that smoking cessation programs should also target females. We cannot rule out underreporting of smoking among females due to cultural reasons. These findings are consistent with previous reports that frequency of stroke in Asian women is less than Asian men but may be higher than European man and women both [24].

In this sample atherosclerosis in the small vessel was responsible for most of the stroke cases. Majority of these patients had dyslipidemia. Hypertension and diabetes were other risk factors that were present in them. Inclusion of large 
TABLE 5: Distribution of covariates among stroke patients in old age.

\begin{tabular}{lccc}
\hline Variable & $\leq 70$ yrs, & $>70$ yrs, & $P$ value \\
& $n=567$ & $n=112$ & \\
\hline Male $n$ (\%) & $385(67.9)$ & $75(67.0)$ & 0.85 \\
Systolic BP mean (SD) & $144.9(22.5)$ & $141.7(21.4)$ & 0.17 \\
Diastolic BP mean (SD) & $85.2(12.3)$ & $81.7(10.9)$ & $<0.01$ \\
RBS mean (SD) & $232.8(97.6)$ & $224.3(79.3)$ & 0.35 \\
TOAST $n$ (\%) & & & \\
Large vessel & $182(32.1)$ & $39(34.8)$ & \\
Small vessel & $267(47.1)$ & $41(36.6)$ & 0.15 \\
Cardioembolic & $27(4.8)$ & $6(5.4)$ & \\
$\quad$ Unknown etiology & $91(16.0)$ & $26(23.2)$ & \\
Risk factors $n$ (\%) & & & \\
DM (RBS $>$ 200) & $436(76.9)$ & $70(62.5)$ & $<0.01$ \\
HTN & $412(72.7)$ & $92(82.1)$ & 0.04 \\
Dyslipidemia & $479(93.6)$ & $92(90.2)$ & 0.23 \\
Smoking & $98(17.3)$ & $12(10.7)$ & 0.09 \\
Carotid stenosis $>70 \%$ & $24(18.9)$ & $4(9.3)$ & 0.14 \\
A-fib on ECG & $7(1.2)$ & $1(0.9)$ & 0.76 \\
Severe LV dysfunction & $259(58.3)$ & $60(68.2)$ & 0.09 \\
Investigations & & & \\
MRI & $124(21.9)$ & $16(14.3)$ & 0.07 \\
Echocardiography & $373(79.7)$ & $71(75.5)$ & 0.37 \\
Carotid Doppler & $413(72.8)$ & $84(75.0)$ & 0.64 \\
Complications & & & \\
Pneumonia & $43(7.6)$ & $17(15.2)$ & 0.01 \\
UTI & $47(8.3)$ & $11(9.8)$ & 0.60 \\
Stroke severity NIHSS $>14$ & $78(13.9)$ & $20(17.9)$ & 0.29 \\
mRs at discharge & & & \\
0-2 & $200(35.3)$ & $27(24.1)$ & \\
3-5 & $354(62.4)$ & $82(73.2)$ & 0.07 \\
Hospital mean stay & $3.6(4.0)$ & 0.54 \\
\hline
\end{tabular}

Atrial fibrillation: A-fib, blood pressure: BP, diabetes mellitus: DM, electrocardiogram: ECG, hypertension: HTN, left ventricular: LV, magnetic resonance imaging: MRI, National Institute of Health Stroke Scale: NIHSS, random blood sugar: RBS, standard deviation: $\mathrm{SD}$, and urinary tract infection: UTI.

number of patients with diabetes may be explained by the fact of the recruitment from BIRDEM General Hospital, a tertiary care hospital run by the Diabetic Association of Bangladesh, only which, however, is 650-bed multidisciplinary hospital. Diabetes was more common among the age group less than or equal to seventy years. Dyslipidemia, hypertension, and diabetes are important risk factors for stroke as reported previously $[19,25,26]$. We found that a very high proportion of the stroke patients (93\%) had dyslipidemia as compared to Pakistan $[20,26]$. Similarly other two important risk factors, that is, diabetes and hypertension, are more common among stroke patients in Bangladesh as compared to Pakistan.

Mortality of the stroke patient was much lower as compared to regional data [20]. This lower mortality can be because of better access to the tertiary care hospitals, better clinical care of the patients, or a combination of the two. An alternative explanation may be that only patients with lesser stroke severity and better prognosis reach to the hospitals. A study designed to specifically answer this uncertainty may be helpful to explore factors responsible for the lower mortality. Burden of stroke is growing in large parts of Asia due to growing age, urbanization, and life style changes. No data is available from Bangladesh related to temporal trends in stroke incidence or stroke types. It is important to follow these trends for future analysis and interventions [27].

This study gives us some critical insight into important aspects of stroke patients in Bangladesh. It is important to make stroke risk scoring tools for this population with the help of the risk factors identified in this study. Stratification of the population with the help of these tools into high, intermediate, and low risk group may help public health practitioners to prevent stroke. It is important to generate contextual evidence for designing composite interventions on the basis of behavior change communication theories for the primary prevention of stroke in this population. Population based studies looking at incidence and prevalence of stroke are much needed. Most studies related to Bangladesh are limited to one or few centers. Large, multicenter studies with nationally representative distribution pattern are required to plan community/population based interventions.

\section{Appendix}

\section{A. Questionnaire}

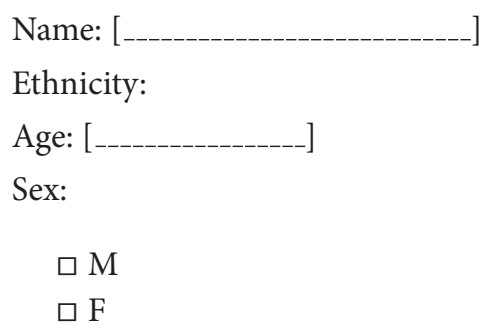

Ph no: $[----------------]$

Add: [ [--_-_-_---_]

Admission date/time: _-_/___/__-_-_: _-_-_ PM/AM

Education:
$\square$ Illiterate
$\square$ Class 1-5
$\square$ Matric or less intermediate
$\square$ graduate
$\square$ Post graduate

Meds on adm:
$\square$ Aspirin
$\square$ Persantin
$\square$ Ticlid
$\square$ Warfarin 
TABLE 6: Results of multiple linear regression with Barthel score as the outcome.

\begin{tabular}{|c|c|c|c|c|}
\hline Variable & Coefficient $(\beta)$ & Standard error (SE) & $95 \% \mathrm{CI}$ & $P$ value \\
\hline Intercept & 78.00 & 5.67 & & \\
\hline mRS ( 4 or above) & -30.11 & 1.50 & -33.01 to -27.20 & $<0.01$ \\
\hline Age & -0.17 & 0.06 & -0.29 to -0.06 & $<0.01$ \\
\hline Systolic blood pressure & -0.07 & 0.03 & -0.12 to -0.01 & 0.03 \\
\hline UTI & -6.08 & 2.43 & -10.85 to -1.30 & 0.01 \\
\hline Pneumonia & -9.64 & 2.42 & -14.39 to -4.90 & $<0.01$ \\
\hline Stroke severity NIHSS $>14$ & -20.86 & 1.95 & -24.69 to -17.03 & $<0.01$ \\
\hline
\end{tabular}

Urinary tract infection: UTI.
$\square$ Plavix
$\square$ AntiHTN
$\square$ Antilipid
$\square$ oral hypoglycemic
$\square$ insulin
$\square$ Others
$\square$ NONE

Blood Pressure At arrival ( $\mathrm{mmHg})$ :

Temp: at arrival: ${ }_{----}{ }^{\circ} \mathrm{C}$

Pulse at arrival (beats per minute):

stroke onset:

$\square$ awake (Time: ${ }_{-----} \mathrm{am} / \mathrm{pm}$ )
$\square$ asleep -------

(If stroke occurs during sleep onset time will be when person retires to bed)

Exact Time (in hours and minutes) between stroke onset and presentation: __- $\mathrm{hrs}_{---}$min

Assoc diagnosis on history:

$\square$ DM
$\square$ HTN
$\square$ Dyslipidemia
$\square$ IHD
$\square$ MI
$\square$ A. fib
$\square$ h/o RHD

Prosthetic valve (which valve? duration

Smoking status:

$\square$ Smoker \# pack/year [--_]

$\square$ Ex smoker \# of years left smoking [----]

$\square$ Non smoker

Tobacco use:

$\square$ chewing tobacco $\square$ shisha/huqqa

$\square$ other form of tobacco;

Alcohol abuse;

current history of alcoholism

Previous stroke:

$$
\begin{aligned}
& \square \mathrm{Y} \\
& \square \mathrm{N} \\
& \text { (hemmorhagic ischemic Unknown). } \\
& \text { If Yes; \# of strokes ( } \left.-{ }_{----}\right)
\end{aligned}
$$

Previous TIA:

$$
\begin{aligned}
& \square \mathrm{Y} \\
& \square \mathrm{N} \\
& \text { If Yes; \# of TIA (_-----) }
\end{aligned}
$$

If DM or HTN:

Retinopathy

$$
\begin{aligned}
& \square \mathrm{Y} \\
& \square \mathrm{N}
\end{aligned}
$$

Proteinuria

$$
\begin{aligned}
& \square \mathrm{Y} \\
& \square \mathrm{N}
\end{aligned}
$$

$\uparrow$ Creatinine

$\square \mathrm{Y}$

$\square \mathrm{N}$

(value) [--------]

Family history:

$\mathrm{F} / \mathrm{H}$ of Stroke in $1^{\circ}$ relative:

$$
\begin{aligned}
& \square \mathrm{Y} \\
& \square \mathrm{N}
\end{aligned}
$$

$\mathrm{F} / \mathrm{H}$ of $\mathrm{IHD}$ in $1^{\circ}$ relative:

$$
\square \mathrm{Y}
$$$$
\square \mathrm{N}
$$ 
NIHSS score [---------]

Rankin:
on Adm
$\square 0$
$\square 1$
$\square 2$
$\square 3$
$\square 4$
$\square 5$
$\square 6$

Rankin:

@ baseline
$\square 0$
$\square 1$
$\square 2$
$\square 3$
$\square 4$
$\square 5$
$\square 6$

(Before stroke onset)

Please mention "not done" if any test is not performed, against the entry

Imaging:

first imaging: normal:

$\square \mathrm{Y}$

$\square \mathrm{N}$

CT Scan or MRI (Circle one)

If Ist image abnormal:

$\square$ Intraparenchymal hemorrhage

$\square$ Intraventricular hemorrhage

$\square$ Established infarct

$\square$ Early infarct (Circle one)

If $>1$ infarct: Number of infarct

Periventricular ischemic changes

$\square \mathrm{Y}$

$\square \mathrm{N}$

Old infarcts:

$\square \mathrm{Y}$

$\square \mathrm{N}$

(Number of infarcts

Subsequent imaging: normal:

$\square \mathrm{Y}$

$\square \mathrm{N}$
CT Scan or MRI or both (Circle one)

MRI

date/time:

Findings [

Intraparenchymal hemorrhage

Intraventricular hemorrhage

volume

New infarct's Size $(\mathrm{cm} \times \mathrm{cm})$

CT

date/time:

Findings [

Intraparenchymal hemorrhage

Intraventricular hemorrhage

volume

New infarct's Size $(\mathrm{cm} \times \mathrm{cm})$ [_-_-_-_]

Old infarcts

number

location

MRA

date/time:

$\square$ Normal

$\square$ Abnormal

$\square$ Variant

If variant:

$\square$ hypoplastic ACA

$\square$ ACAs filling from one side

$\square$ absent vertebral

$\square$ small/hypoplastic

$\square$ vertebral

$\square$ PCAfilling through PCom

diffuse atherosclerodis in MRA:
$\square$ ant circ
$\square$ post circ
$\square$ both

focal stenosis of specific region in MRA:

$\square \mathrm{Y}$

$\square \mathrm{N}$

region [-_-_-_]

focal occlusion of specific region in MRA:

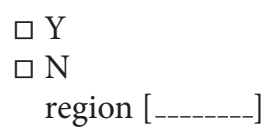

Hemorrhagic Conversion:

$\square \mathrm{Y}$

$\square \mathrm{N}$

Mass effect:

$\square \mathrm{Y}$ 
$\square \mathrm{N}$

Midline shift

$$
\begin{aligned}
& \square \mathrm{Y} \\
& \square \mathrm{N} \\
& \quad\left[\_---\right] \mathrm{mm}
\end{aligned}
$$

Imaging Findings (New Stroke)

Vascular teretories (can be more than one response):

$\square$ ant cerebral

$\square$ middle cerebral

$\square$ Watershed

$\square$ Vertebrobasilar posterior cerebral

Location of infarct or hemorrhage:

$\square$ Right frontal

$\square$ Left Frontal

$\square$ Right Parietal

$\square$ Left Parietal

$\square$ Right Temporal

$\square$ Left Temporal

$\square$ Right Occipital

$\square$ Left Occipital

$\square$ Right basal ganglia

$\square$ Left Basal Ganglia

$\square$ Right Thalamus

$\square$ Left Thalamus

$\square$ Right Internal capsule

$\square$ Left Internal Capsule

$\square$ Right subcortical

$\square$ Left Subcortical

$\square$ Right Midbrain

$\square$ Left Midbrain

$\square$ Right Pons

$\square$ Left Pons

$\square$ Right Medulla

$\square$ Left Medulla

$\square$ Right Cerebellar hemisphere

$\square$ Left Cerebellar Hemishere

$\square$ Vermis

Workup

CXR

$\square \mathrm{nl}$

$\square$ pneum cardiomeg

$\square$ pulm edema

$\square$ effusion

$\square$ other (specify):
EKG

$\square \mathrm{nl}$

$\square$ new Infarct

$\square$ old infarct

$\square$ Ischemia

$\square \mathrm{BBB}(\mathrm{LBBB} / \mathrm{RBBB})$

$\square$ A fib

$\square \mathrm{LAD}$

$\square$ LVH Other (specify): (Specify location/region of infarct)

Blood sugar at admission (mg/dL):

Troponin:

$\square$ Normal
$\square$ Elevated

$\mathrm{Hb} / \mathrm{Hct}$ :

Red cell count:

TLC/DLC:

Platelet:

Hemoglobin;

lipids [Total Chol: _-- Triglyc: _-- TL: _-- HDL: --_ LDL: _-_]

Hypercoag state:

$\square \mathrm{Y}$

$\square \mathrm{N}$

$\square$ not assessed

protein $\mathrm{C}\left({ }_{---} \%\right)$,

protein S (_-_-_\%),

antithrombin III (_--_-_)

PT/INR (_---_)

Aptt (_----)

Serum Homocysteine level (_---_)

Factor VIII level (_----_)

Antiphospholipid AB:

$\square+\mathrm{ve}$

$\square-\mathrm{ve}$

$\square$ Not done

Transthoracic Echo or transthoracic echo (Circle):

$$
\begin{aligned}
& \square \text { done } \\
& \square \text { not done }
\end{aligned}
$$

left vent wall motion abnormalties

$\square \mathrm{Y}$

$\square \mathrm{N}$ 
left vent systolic function

$\square$ severe ef $<35 \%$

$\square$ moderate ef $35-50 \%$

$\square$ mild ef 50-55\%

$\square$ normal

Ejection fr [_-_-_-_-- $] \%$

Thrombus

\section{$\square \mathrm{Y}$ \\ $\square \mathrm{N}$}

location [

Valvular disease

$\square \mathrm{Y}$
$\square \mathrm{N}$
$\square$ mit sten
$\square$ mit regurg
$\square$ mit prol
$\square$ aort
$\square$ other [----------]

Atrial dilat
$\square \mathrm{Y}$
$\square \mathrm{N}$
$\square$ Left
$\square$ Right
$\square$ both

LVH:

$\square \mathrm{Y}$

$\square \mathrm{N}$

LVDD:
$\square \mathrm{Y}$
$\square \mathrm{N}$

Vent dilat
$\square \mathrm{Y}$
$\square \mathrm{N}$
$\square$ Left
$\square$ Right
$\square$ Both

R-L shunt
$\square \mathrm{Y}$
$\square \mathrm{N}$

PFO

$\square \mathrm{Y}$

$\square \mathrm{N}$

ASD

\section{$\square \mathrm{Y}$}

$\square \mathrm{N}$

Abnormalities in arch of aorta (Specify):

Carotid Doppler:

$$
\begin{aligned}
& \square \mathrm{Nl} \\
& \square \text { Abnl } \\
& \square \text { not done }
\end{aligned}
$$

$\mathrm{R}$ int crtd plaq
$\square \mathrm{Y}$
$\square \mathrm{N}$
$\square$ Ulcerated
$\square$ Calcified
$\square$ Both
$\square$ Neither\% stenosis [_-_\%_-]

L int crtd plaq
$\square \mathrm{Y}$
$\square \mathrm{N}$
$\square$ Ulcerated
$\square$ Calcified
$\square$ Both

$\square$ Neither\% stenosis [__\%_-]

ANY OTHER WORK UP:

Hospital Course

Received tPA
$\square \mathrm{Y}$
$\square \mathrm{N}$

(Reason

Complications/Events:
$\square$ DVT
$\square$ Pneumonia
$\square \mathrm{UTI}$
$\square$ GI hem
$\square$ Bedsore

$\square$ Stroke

$\square$ TIA

$\square$ Angina

$\square \mathrm{MI}$ 


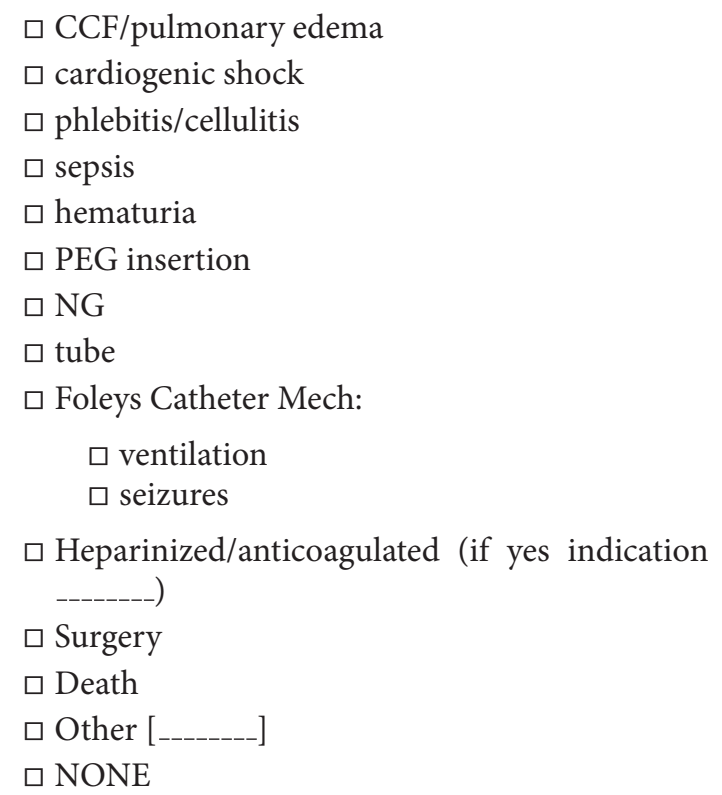

Discharge

Diagnosis;

$\square$ Ischemic stroke

$\square$ Hemorrhagic stroke

Discharge Diagnosis on TOAST criteria (for ischemic stroke):

$\square$ Large vsl thrombotic

$\square$ Small vsl thrombotic

$\square$ Cardioemb

$\square$ Unknown or ill-defined etiology

$\square$ Other definite etiology (Specify _-_--)

$\square$ Cerebral venous thrombosis

New diagnosis:

$\square$ HTN

$\square \mathrm{DM}$

$\square$ Dyslipidemia

$\square$ CAD

Hospital stay: [_-_-_] days

Stroke Severity at Discharge

NIHSS:

Rankin (MRS):

$\square 0$

$\square 1$

$\square 2$

$\square 3$

$\square 4$ $\square 5$

$\square 6$

Medications at discharge:
$\square$ ASA
$\square$ Warf
$\square$ Perstn Ticlid
$\square$ ASA + Prstn
$\square$ Plavix
(Specify drugs on the following)
$\square$ Anti HTN
$\square$ Antilipid
$\square$ oral hypoglycemic
$\square$ insulin antibiotics
$\square$ Other [

Disposition:

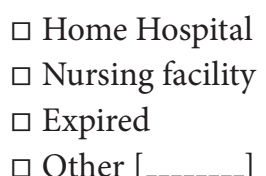

30 day follow up:

Rankin (MRS):
$\square 0$
$\square 1$
$\square 2$
$\square 3$
$\square 4$
$\square 5$
$\square 6$

Recurrent stroke

$$
\text { yes/no }
$$

6 months follow up

Rankin (MRS):
$\square 0$
$\square 1$
$\square 2$
$\square 3$
$\square 4$
5
$\square 6$

Recurrent stroke

$$
\text { yes/no }
$$

One year follow up:

Rankin (MRS): 

$\square 0$
$\square 1$
$\square 2$
$\square 3$
$\square 4$
$\square 5$
$\square 6$

Recurrent stroke

yes/no

\section{B. National Institutes of Health Stroke Scale}

Level of Consciousness:

$0=$ Alert

1 = Not alert, but arousable with minimal stimulation

$2=$ Not alert, requires repeated stimulation to attend

$3=$ Coma

Questions (ask patient the Month and their age)

$0=$ Answers both correctly

$1=$ Answers one correctly

$2=$ Answers neither correctly

Commands (Ask patient $\{1\}$ to open and close eyes and $\{2\}$ make fist)

$$
\begin{aligned}
& 0=\text { Performs both tasks correctly } \\
& 1=\text { Performs one task correctly } \\
& 2=\text { Performs neither task }
\end{aligned}
$$

Gaze (only horizontal gaze)

$$
\begin{aligned}
& 0=\text { Normal } \\
& 1=\text { Partial gaze palsy } \\
& 2=\text { Total gaze palsy }
\end{aligned}
$$

Visual fields

$$
\begin{aligned}
& 0=\text { No visual loss } \\
& 1=\text { Partial hemianopsia } \\
& 2=\text { Complete hemianopsia } \\
& 3=\text { Bilateral; hemianopsia }
\end{aligned}
$$

Facial Palsy

$$
\begin{aligned}
& 0=\text { Normal } \\
& 1=\text { Minor paralysis } \\
& 2=\text { Partial paralysis } \\
& 3=\text { Complete paralysis }
\end{aligned}
$$

Motor arm (score each arm separately)
$0=$ No drift (Able to keep arm extended at $90^{\circ}$ while sitting or $45^{\circ}$ while lying, with out drift for 10 seconds)

$1=$ Drift before five seconds

$2=$ Fall before ten seconds

$3=$ No effort against gravity

$4=$ No movement

Motor leg (score each leg separately)

$0=$ No drift (Able to keep leg extended at $30^{\circ}$ with out drift for 10 seconds)

$1=$ Drift before five seconds

$2=$ Fall before ten seconds

$3=$ No effort against gravity

$4=$ No movement

Ataxia

$$
\begin{aligned}
& 0=\text { Absent }, \text { no ataxia } \\
& 1=\text { One limb } \\
& 2=\text { Two limbs }
\end{aligned}
$$

Sensory

$$
\begin{aligned}
& 0=\text { Normal } \\
& 1=\text { Mild loss } \\
& 2=\text { Severe loss }
\end{aligned}
$$

Language

$$
\begin{aligned}
& 0=\text { Normal } \\
& 1=\text { Mild Aphasia } \\
& 2=\text { Severe aphasia } \\
& 3=\text { Mute or global aphasia }
\end{aligned}
$$

Dysarthria

$$
\begin{aligned}
& 0=\text { Normal } \\
& 1=\text { Mild } \\
& 2=\text { Severe }
\end{aligned}
$$

$11=$ Extinction and inattention

$$
\begin{aligned}
& 0=\text { Normal } \\
& 1=\text { Mild } \\
& 2=\text { Severe }
\end{aligned}
$$

\section{Modified Rankin Scale}

Grade 0; Normal

Grade 1; Minor symptoms without disability, able to perform prior activities

Grade 2; Slightly disabled but can walk and do self care without assistance 
Grade 3; Moderately disabled, needing some help but can walk unaided

Grade 4; Moderate to severe disability, unable to walk, needing some help in ADL

Grade 5: Severly disabled, bedridden, requiring constant care

Grade 6: Death

\section{Barthel Index}

Feeding

$0=$ unable

$5=$ needs help cutting, spreading butter, and so forth, or requires modified diet

$10=$ independent

Bathing

$0=$ dependent

5 = independent (or in shower)

Grooming

$0=$ needs to help with personal care

5 = independent face/hair/teeth/shaving (implements provided)

Dressing

$0=$ dependent

$5=$ needs help but can do about half unaided

10 = independent (including buttons, zips, laces, etc.)

Bowels

$0=$ incontinent (or needs to be given enemas)

$5=$ occasional accident

$10=$ continent

Bladder

$0=$ incontinent, or catheterized and unable to manage alone

$5=$ occasional accident

$10=$ continent

Toilet Use

$0=$ dependent

$5=$ needs some help, but can do something alone

10 = independent (on and off, dressing, wiping)

Transfers (bed to chair, and back)

$0=$ unable, no sitting balance
$5=$ major help (one or two people, physical), can

sit

$10=$ minor help (verbal or physical)

$15=$ independent

Mobility (on level surfaces)

$0=$ immobile or $<50$ yards

$5=$ wheelchair independent, including corners, $>50$ yards

$10=$ walks with help of one person (verbal or physical) $>50$ yards

15 = independent (but may use any aid; e.g., stick) $>50$ yards

Stairs

$0=$ unable

5 = needs help (verbal, physical, carrying aid)

$10=$ independent

TOTAL (0-100):

\section{Competing Interests}

The authors declare that they have no competing interests.

\section{Acknowledgments}

The work was supported by Sanofi Bangladesh Limited.

\section{References}

[1] W. A. Zoghbi, T. Duncan, E. Antman et al., "Sustainable development goals and the future of cardiovascular health: a statement from the global cardiovascular disease taskforce," Journal of the American Heart Association, vol. 3, no. 5, Article ID e000504, 2014.

[2] S. Mendis and B. Norrving, "Organizational update world health organization," Stroke, vol. 45, no. 2, pp. e22-e23, 2014.

[3] A. S. Kim and S. C. Johnston, "Global variation in the relative burden of stroke and ischemic heart disease," Circulation, vol. 124, no. 3, pp. 314-323, 2011.

[4] R. V. Krishnamurthi, A. E. Moran, M. H. Forouzanfar et al., "The global burden of hemorrhagic stroke: a summary of findings from the GBD 2010 study," Global Heart, vol. 9, no. 1, pp. 101106,2014

[5] C. J. L. Murray, T. Vos, R. Lozano et al., "Disability-adjusted life years (DALYs) for 291 diseases and injuries in 21 regions, 19902010: a systematic analysis for the Global Burden of Disease Study 2010," The Lancet, vol. 380, no. 9859, pp. 2197-2223, 2012.

[6] B. Norrving and B. Kissela, "The global burden of stroke and need for a continuum of care," Neurology, vol. 80, no. 3, supplement 2, pp. S5-S12, 2013.

[7] D. R. Gwatkin, A. Bhuiya, and C. G. Victora, "Making health systems more equitable," The Lancet, vol. 364, no. 9441, pp. 12731280, 2004.

[8] M. Wasay, I. A. Khatri, and S. Kaul, "Stroke in South Asian countries," Nature Reviews Neurology, vol. 10, no. 3, pp. 135-143, 2014. 
[9] M. N. Islam, M. Moniruzzaman, M. I. Khalil et al., "Burden of stroke in Bangladesh," International Journal of Stroke, vol. 8, no. 3, pp. 211-213, 2013.

[10] Q. D. Mohammad, M. Habib, A. Hoque et al., "Prevalence of stroke above forty years," Mymensingh Medical Journal, vol. 20, no. 4, pp. 640-644, 2011.

[11] A. Hossain, N. Ahmed, M. Rahman, M. Islam, G. Sadhya, and K. Fatema, "Analysis of sociodemographic and clinical factors associated with hospitalized stroke patients of Bangladesh," Faridpur Medical College Journal, vol. 6, no. 1, pp. 19-23, 2011.

[12] M. A. N. Siddique, Z. Nur, M. S. Mahbub, M. B. Alam, and M. T. Miah, "Clinical presentation and epidemiology of stroke: a study of 100 cases," Journal of Medicine, vol. 10, no. 2, pp. 86-89, 2009.

[13] M. T. Miah, A. A. Hoque, B. K. Tarafder, S. M. A. Romel, and M. K. Hassan, "Stroke in young age-study of 50 cases," Journal of Medicine, vol. 9, no. 1, pp. 10-15, 2008.

[14] M. Badiuzzaman, F. R. Mohammed, F. R. Chowdhury, M. S. Bari, M. B. Alam, and H. A. M. N. Ahasan, "Prevalence of modifiable risk factors among stroke patients in a tertiary care hospital in Dhaka," Journal of Medicine, vol. 10, supplement 1 , pp. 18-21, 2009.

[15] F. J. Mateen, "International issues: neurology in Bangladesh," Neurology, vol. 74, no. 2, pp. e5-e8, 2010.

[16] A. Sajjad, R. Chowdhury, J. F. Felix et al., "A systematic evaluation of stroke surveillance studies in low- and middleincome countries," Neurology, vol. 80, no. 7, pp. 677-684, 2013.

[17] S. K. Das, "Who steps stroke surveillance system: feasibility in India," Indian Journal of Medical Research, vol. 130, no. 4, pp. 359-360, 2009.

[18] D. Nagaraja, G. Gururaj, N. Girish et al., "Feasibility study of stroke surveillance: data from Bangalore, India," Indian Journal of Medical Research, vol. 130, no. 4, pp. 396-403, 2009.

[19] R. Basri, M. M. Shaik, M. K. Alam, M. B. A. Mondol, Q. D. Mohammad, and S. H. Gan, "Waist to hip ratio, waist to height ratio and body mass index predict stroke risk in a Bangladeshi population," International Medical Journal, vol. 20, no. 6, pp. 740-743, 2013.

[20] B. A. Khealani, M. Khan, M. Tariq et al., "Ischemic strokes in Pakistan: observations from the national acute ischemic stroke database," Journal of Stroke and Cerebrovascular Diseases, vol. 23, no. 6, pp. 1640-1647, 2014.

[21] S. Arora, J. P. Broderick, M. Frankel et al., "Acute stroke care in the US: results from 4 pilot prototypes of the Paul Coverdell National Acute Stroke Registry," Stroke, vol. 36, no. 6, pp. 12321240, 2005.

[22] B. I. Lee, H. S. Nam, J. H. Heo, and D. I. Kim, "Yonsei Stroke Registry. Analysis of 1,000 patients with acute cerebral infarctions," Cerebrovascular Diseases, vol. 12, no. 3, pp. 145-151, 2001.

[23] T. Moulin, L. Tatu, T. Crépin-Leblond, D. Chavot, S. Bergès, and L. Rumbach, "The Besancon Stroke Registry: an acute stroke registry of 2500 consecutive patients," European Neurology, vol. 38, no. 1, pp. 10-20, 1997.

[24] P. Mehndiratta, M. Wasay, and M. M. Mehndiratta, "Implications of female sex on stroke risk factors, care, outcome and rehabilitation: an asian perspective," Cerebrovascular Diseases, vol. 39, no. 5-6, pp. 302-308, 2015.

[25] J. Djelilovic-Vranic, A. Alajbegovic, V. Zelija-Asimi et al., "Predilection role diabetes mellitus and dyslipidemia in the onset of ischemic stroke," Medicinski arhiv, vol. 67, no. 2, pp. 120-123, 2013.
[26] Z. Basharat, S. Mumtaz, F. Rashid et al., "Prevalence of risk factors of ischemic stroke in a local Pakistani population. Highdensity lipoproteins, an emerging risk factor," Neurosciences (Riyadh), vol. 17, no. 4, pp. 357-362, 2012.

[27] M. M. Mehndiratta, M. Khan, P. Mehndiratta, and M. Wasay, "Stroke in Asia: geographical variations and temporal trends," Journal of Neurology, Neurosurgery and Psychiatry, vol. 85, pp. 1308-1312, 2014 


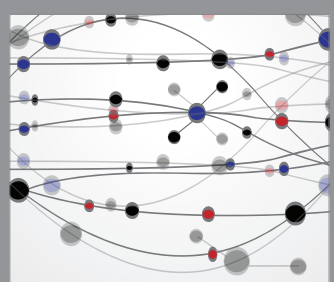

The Scientific World Journal
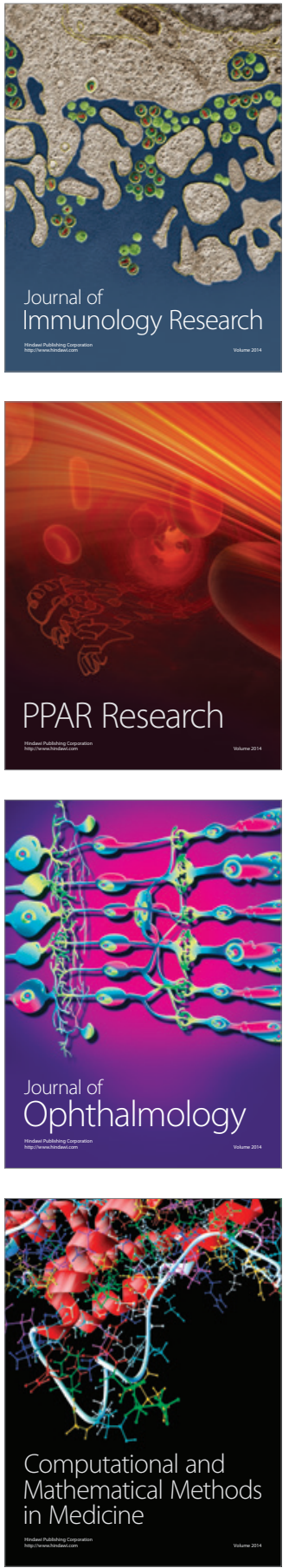

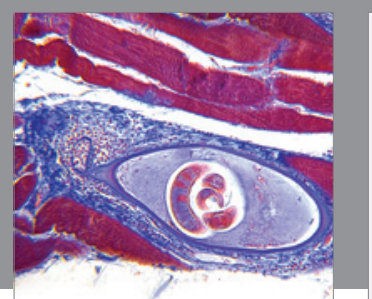

Gastroenterology Research and Practice

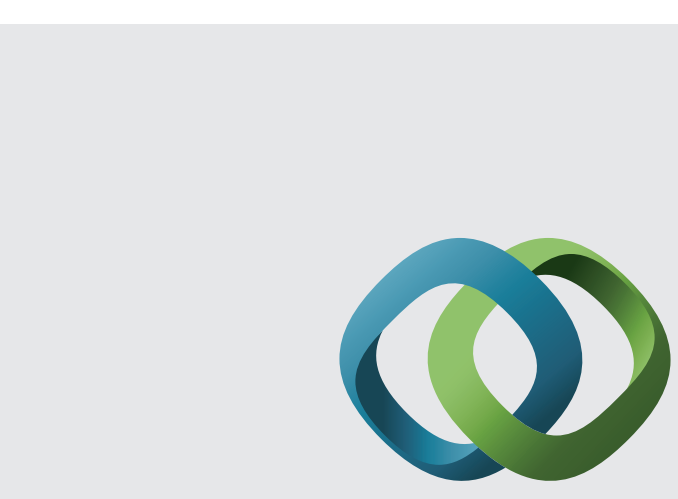

\section{Hindawi}

Submit your manuscripts at

http://www.hindawi.com
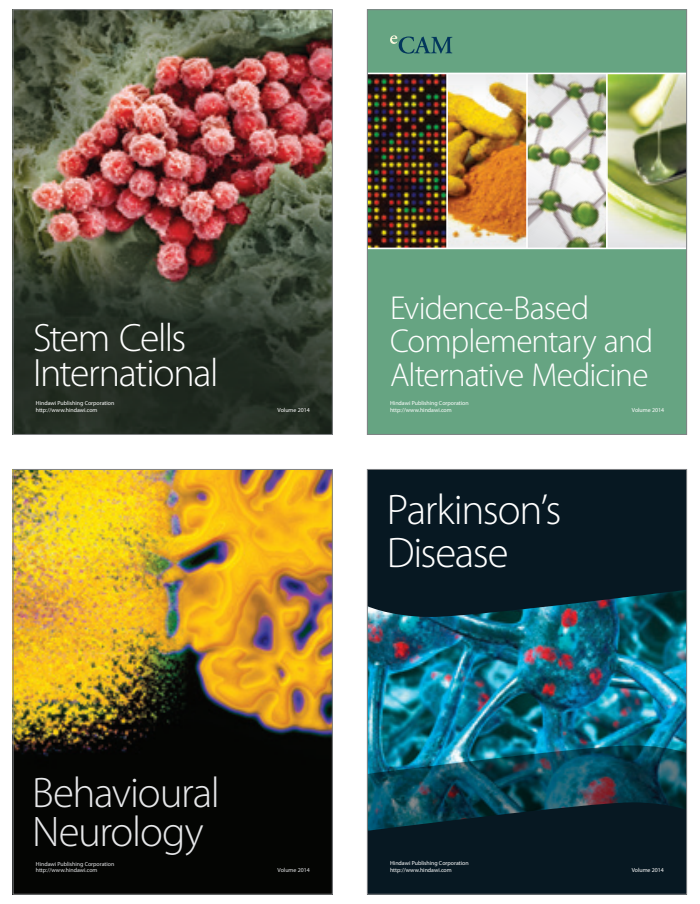
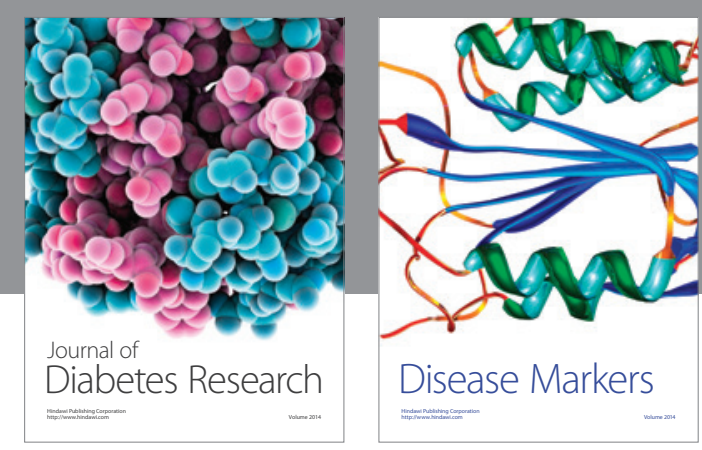

Disease Markers
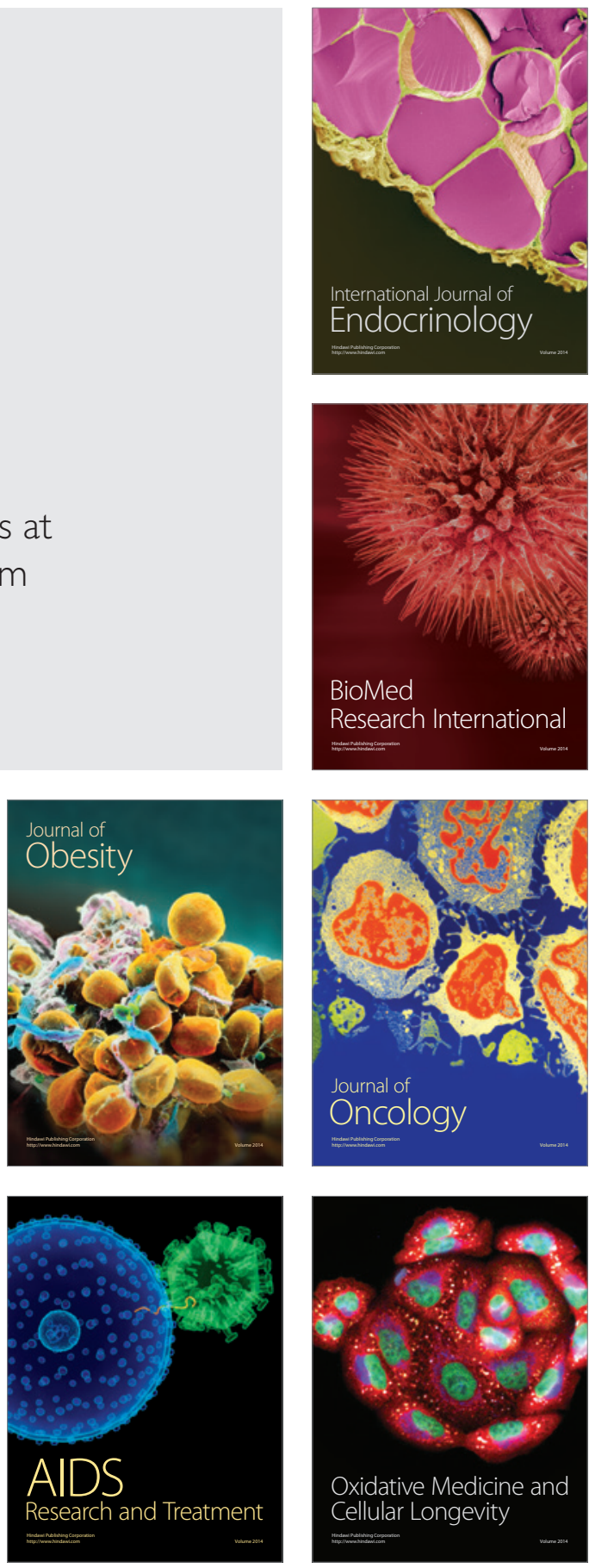